\title{
Prospective Audit of Exudative Age-Related Macular Degeneration: 12-Month Outcomes in Treatment-Naïve Eyes
}

\author{
Mark C. Gillies, ${ }^{1}$ Richard Walton, ${ }^{1}$ Judy M. Simpson, ${ }^{2}$ Jennifer J. Arnold, ${ }^{3}$ Robyn H. Guymer, ${ }^{4}$ \\ Ian L. McAllister, ${ }^{5}$ Alex P. Hunyor, ${ }^{1,6}$ Rohan W. Essex, ${ }^{7}$ Nigel Morlet, ${ }^{8}$ and Daniel Barthelmes ${ }^{1,9}$ \\ for the Fight Retinal Blindness! Project Investigators
}

\author{
${ }^{1}$ The Save Sight Institute, Sydney Medical School, The University of Sydney, Sydney, New South Wales, Australia \\ ${ }^{2}$ School of Public Health, University of Sydney, Sydney New South Wales, Australia \\ ${ }^{3}$ Marsden Eye Specialists, Parramatta, New South Wales, Australia \\ ${ }^{4}$ Centre for Eye Research Australia, University of Melbourne, Royal Victorian Eye and Ear Hospital, Victoria, Australia \\ ${ }^{5}$ Lions Eye Institute, Centre for Ophthalmology and Vision Science, University of Western Australia, Western Australia \\ ${ }^{6}$ Retina Associates, Chatswood, New South Wales, Australia \\ ${ }^{7}$ Academic Unit of Ophthalmology, Australian National University, Acton, Australia \\ ${ }^{8}$ University of Western Australia Department of Population Health, Perth, Western Australia \\ ${ }^{9}$ Department of Ophthalmology, University Hospital Zurich, University of Zurich, Zurich, Switzerland
}

Correspondence: Mark C. Gillies, Save Sight Institute, South Block, 8 Macquarie Street, Sydney NSW 2000, Australia;

mark.gillies@sydney.edu.au.

See the Appendix for the Fight Retinal Blindness! Project Investigators.

Submitted: March 7, 2013

Accepted: June 21, 2013

Citation: Gillies MC, Walton R, Simpson JM, et al. Prospective audit of exudative age-related macular degeneration: 12-month outcomes in treatment-naïve eyes. Invest Ophthalmol Vis Sci. 2013;54:5754-5760. DOI: 10.1167/iovs.13-11993
Purpose. We report the 12-month outcomes of 1140 treatment-naïve eyes with exudative agerelated macular degeneration (wet AMD) who were treated for 12 months with intravitreal anti-VEGF drugs in routine clinical practice.

Methods. Index visit characteristics, such as lesion type and size, visual acuity (VA, in Logarithm of the Minimal Angle of Resolution [logMAR] letters), as well as treatments, outcomes (VA, lesion activity status) and ocular adverse events were recorded in a prospectively designed electronic database. Index visit characteristics associated with the 12-month VA outcome were identified using mixed effects linear regression.

RESUlts. Mean change in VA in the cohort after 12 months was +4.7 logMAR letters (95\% confidence interval $[\mathrm{CI}], 3.4-6.1)$ with a mean of 7.0 injections. No significant difference was found in change in VA, or number of injections by type or size of the lesion. Median time to inactivation of lesions was 194 days. VA at the index visit was the strongest predictor for the 12-month outcomes. Infectious endophthalmitis occurred in 2 cases, and retinal detachment occurred in 1 case from a total of 9162 injections.

Conclusions. These findings indicate that VEGF inhibitors can achieve reasonably good outcomes for wet AMD when used in routine clinical practice.

Keywords: anti-VEGF, observational study, neovascular age-related macular degeneration
W hile the efficacy of ranibizumab (Lucentis; Novartis, Basel, Switzerland), bevacizumab (Avastin; HoffmanLaRoche, Basel, Switzerland), and aflibercept (Eylea; Bayer, Basel, Switzerland) for exudative age-related macular degeneration (wet AMD) ${ }^{1}$ has been demonstrated convincingly by tightly controlled phase 3 clinical trials, ${ }^{2-7}$ it still is not certain whether the results of these studies will be replicated in the real world after the new drugs have been approved for general use. Many patients being treated for wet AMD in the general community may not have met inclusion criteria of the clinical trials. Even if they had, a heavy treatment burden on all involved in routine retinal practice has led to dosing regimens that are less intensive than those used in the pivotal trials, such as the pro re nata (PRN) and treat-and-extend regimens. ${ }^{8,9}$

The Fight Retinal Blindness! (FRB) Project has established a prospective audit system that can track anonymously outcomes of treatment of retinal disease, such as wet AMD, in large numbers of patients treated in routine retinal treatment centers. ${ }^{10}$ Here, we describe the 12 -month outcomes, including visual acuity (VA), grading of lesion activity, and adverse events, for 1140 treatment-naive participants in the FRB! Project wet AMD audit.

\section{MeTHODS}

\section{Study Design and Setting}

This is an observational study utilizing anonymized longitudinal data from the FRB registry that were captured during routine clinical practice. All treatment decisions and visit schedules were entirely at the discretion of the treating physician and patient. Details of the FRB project data tracking system have been reported previously. ${ }^{10}$ The research followed the tenets of the Declaration of Helsinki. Patients were given information regarding the project and given the opportunity to opt out of the project. Each of the three academic core centers from the Universities of Sydney, Melbourne, and Western Australia 
Table 1. Index Visit Characteristics of Eyes That Completed 12 Months of Follow-up and Those That Did Not

\begin{tabular}{lll}
\hline \multicolumn{1}{c}{ Characteristic } & \multicolumn{1}{c}{$\begin{array}{c}\text { 12-Month } \\
\text { Completers }\end{array}$} & Noncompleters \\
\hline Eyes & 1140 & 230 \\
Visits & 10,758 & 1,496 \\
$\begin{array}{l}\text { Median days follow-up }\left(\mathrm{Q}_{1},\right. \\
\quad\end{array}$ & - & $210(111,302)$ \\
$\left.\quad \mathrm{Q}_{3}\right)$ & $57.1(45,69)$ & $52.5(40,65)$ \\
Mean index VA $\left(\mathrm{Q}_{1}, \mathrm{Q}_{3}\right)$ & $79.3(75,85)$ & $79.9(75,85)$ \\
Mean age $\left(\mathrm{Q}_{1}, \mathrm{Q}_{3}\right)$ & 61.3 & 58.3 \\
Female, \% & $2000(1300,3050)$ & $2315(1500,3390)$ \\
Median GLD $\left(\mathrm{Q}_{1}, \mathrm{Q}_{3}\right)$ & & \\
Lesion type & $529(53.6)$ & $109(51.4)$ \\
$\quad \begin{array}{l}\text { Occult, } n(\%) \\
\text { Minimally classic, } n(\%)\end{array}$ & $211(21.4)$ & $50(23.6)$ \\
$\begin{array}{l}\text { Predominantly classic, } n \\
\text { (\%) }\end{array}$ & $171(17.3)$ & $43(20.3)$ \\
$\begin{array}{l}\text { Other, } n \text { (\%) } \\
\text { Unclassified, } n\end{array}$ & $76(7.7)$ & $10(4.7)$ \\
\hline
\end{tabular}

obtained approval from their respective Human Research Ethics Committees (HREC) to conduct the project as a quality assurance activity. Overarching ethical approval for the other centers was obtained from the HREC of the Royal Australian and New Zealand College of Ophthalmologists.

Patient data recorded from 27 retinal specialists located across Australia from January 2006 until September 2012 were aggregated for analysis. The project began collecting data from the core centers in Sydney, Melbourne, and Perth, and then spread to nonacademic retinal services in the capital cities of most Australian states.

\section{Participants and Variables}

Few eligibility criteria were applied beyond treatment-naïve eyes commencing treatment for wet AMD that had been diagnosed by their treating ophthalmologist with VA $>20$ letters. All eyes in the database that commenced treatment between January 2004 and November 2011 were included in this analysis, so that all potentially had 12 months of follow-up. At the index visit, that is the visit at which treatment was commenced, the study participants' age; angiographic lesion criteria, such as lesion type and greatest linear dimension (GLD); VA (Logarithm of the Minimum Angle of Resolution [LogMAR], recorded as letters read); choroidal neovascularization (CNV) status (active, inactive); along with treatment history; and treatment decisions (treated or not treated and name of drug used) were recorded. Investigators were asked to enter whichever VA reading was best: uncorrected, corrected, or pinhole. The best VA achieved during each visit was used for analysis. The judgement of "active" or "inactive" was left to the investigator's discretion, thus reflecting real-world practice. It was suggested that users should grade lesions as active if there was intra- or subretinal fluid, or any other feature present that could be attributed to activity of the neovascular lesion. Follow-up visits recorded subsequent VA, CNV status, all treatment decisions, and any ocular adverse events. Three subgroups of interest were prespecified: occult lesions (OC), minimally classic lesions (MC), and predominantly classic lesions (PC).

\section{Statistical Methods}

For continuous variables means or medians and interquartile range $(\mathrm{Q} 1, \mathrm{Q} 3)$ were computed. Of the patients $17 \%$ contributed both eyes to the study database; when measuring variation and performing statistical tests at the index visit, fellow eyes were removed randomly to ensure any possible intereye correlation would not bias estimates. Formal comparisons were made using the nonparametric Kolmogorov-Smirnoff (KS) test, which is sensitive to any difference in the underlying distribution of two samples.

The outcomes analysis used data from all eyes that completed 12 months follow-up, while the safety analysis set included all available data over 12 months. We also examined outcomes for eyes that did not complete 12 months of followup due to withdrawal from treatment or loss to follow-up. Study endpoints included 12-month longitudinal VA, time from first intravitreal injection to inactivation of $\mathrm{CNV}$, and change in CNV status over 12 months. Within-eye changes in VA over 12 months were tested using the paired $t$-test. Longitudinal VA data were plotted using a Lowess smoothed regression line. ${ }^{11,12} \mathrm{~A}$ mixed effects regression model was fitted to the longitudinal VA data to examine the effects of lesion type, GLD, and age on VA at 12 months.

Kaplan-Meier analysis ${ }^{13}$ was used to examine time from first injection to inactivation of CNV status. All observed adverse events were tabulated and reported. Analysis and plots were done using $\mathrm{R}$ version 2.15.0. ${ }^{14}$

\section{Results}

There were 1140 eyes that completed 12 months follow-up (10,758 visits). The study population was $61 \%$ female and the mean age was 79.3 years $\left(\mathrm{Q}_{1}, \mathrm{Q}_{3} ; 75,85\right)$. Mean VA at the index visit was 57.1 letters $\left(Q_{1}, Q_{3} ; 45,69\right.$, Table 1$)$. Due to the quality assurance features of the FRB web-based data entry system, data quality was high for all variables $(>99.5 \%$ complete) with the exception of GLD (80\% complete) and lesion type ( $88 \%$ complete).

\section{Treatment Administered}

A total of 8013 injections was given to the 1140 eyes that completed 12 months, a mean $\left(\mathrm{Q}_{1}, \mathrm{Q}_{3}\right)$ of $7.0(5,9)$ injections per eye (Table 2). The mean number of injections by lesion type was similar. The majority of injections administered were ranibizumab (91\%) irrespective of lesion type, with the remainder being bevacizumab. For all lesion types the interval

TABLE 2. Injection Frequency and Type Over 12 Months of Follow-up

\begin{tabular}{|c|c|c|c|c|}
\hline & Occult & Min Class & Pred Class & All \\
\hline Mean $\left(\mathrm{Q}_{1}, \mathrm{Q}_{3}\right) n$ of injections & $7.0(5,9)$ & $6.8(5,9)$ & $7.1(5,9)$ & $7.0(5,9)$ \\
\hline Median $\left(Q_{1}, Q_{3}\right)$ d between injections when active & $35(28,52)$ & $41(29,55)$ & $35(28,56)$ & $36(28,56)$ \\
\hline Median $\left(Q_{1}, Q_{3}\right)$ d between injections when inactive & $43(35,63)$ & $49(36,63)$ & $42(33,56)$ & $42(35,63)$ \\
\hline$\%$ Ranibizumab injections & $91.3 \%$ & $92.3 \%$ & $91.4 \%$ & $91.4 \%$ \\
\hline
\end{tabular}

Min Class, minimally classic; Pred, predominantly. 
TABLe 3. Index Visit VA and GLD With VA Change After 12 Months

\begin{tabular}{lcccc}
\hline & Occult & Min Class & Pred Class & All \\
\hline Mean $\left(\mathrm{Q}_{1}, \mathrm{Q}_{3}\right)$ VA index visit & $58.9(50,70)$ & $57.1(44,67)$ & $51.8(37,64)$ & $57.1(45,69)$ \\
Mean 12 mo VA change $\left(95 \% \mathrm{CI}^{*}\right)$ & $4.9(2.1-7.1)$ & $4.5(1.9-7.1)$ & $5.1(1.9-8.2)$ & $4.7(3.4-6.1)$ \\
Median $\left(\mathrm{Q}_{1}, \mathrm{Q}_{3}\right)$ index GLD & $2080(1255,3200)$ & $2015(1525,3030)$ & $1740(1065,2555)$ & $2000(1300,3050)$ \\
\hline
\end{tabular}

${ }^{*}$ Bias corrected and accelerated bootstrap 95\% CIs. ${ }^{15}$

between injections was greater when lesions were graded as inactive than when they were graded as active.

\section{VA and GLD at the Index Visit}

There were notable differences in the distributions of VA and GLD among the lesion type subgroups (Table 3, Fig. 1). ${ }^{15}$ VA when starting treatment was lower for the PC classic group than the OC subgroup ( $P<0.0001$, KS test) and the MC subgroup $(P=0.01, \mathrm{KS}$ test). GLD was lower in the PC group than either OC or MC: OC versus PC $(P=0.002)$, MC versus PC $(P=0.005)$, and $\mathrm{OC}$ versus $\mathrm{MC}(P=0.5$, Fig. 1$)$.

\section{Unadjusted 12-Month VA Outcomes}

The mean within-eye change in VA was a +4.7 letter improvement (95\% confidence interval [CI], 3.4-6.1) for the study population as a whole. Similar clinically relevant mean improvements were observed for all subgroups (Fig. 2A): OC +4.9 letters (95\% CI, 2.1-7.1), MC +4.5 letters (95\% CI, 1.97.1), and PC +5.1 letters (95\% CI, 1.9-8.2). The Lowess lines indicated that all three groups exhibited a monotonic improvement throughout 12 months (Fig. 2B).

\section{Modelled 12-Month VA Outcomes}

Given the observed imbalance at the index visit in VA and GLD for the 3 subgroups, a mixed effects regression model was fitted to the longitudinal VA measurements to mitigate potential confounding influences (Table 4). The model coefficients for the MC and PC lesions (relative to OC) of -1.3 and -0.5 , respectively, indicated that lesion subgroup had very little effect $(<1.5$ LogMAR letters) on VA outcomes. The coefficient for age of -0.03 indicated slightly worse outcomes with increasing age: a three decade increase in age was associated with a decreased gain of 1 LogMAR letter after 12 months of treatment. A $1 \mathrm{~mm}(1000 \mu \mathrm{m})$ increase in GLD was associated with a reduced gain of 0.5 letters. The coefficient for time indicated an annual mean improvement of 3.1 letters. VA at the index visit was a highly significant predictor of outcome.

\section{Lesion Activity Over 12 Months}

The median time from first intravitreal injection to lesions being graded as "inactive" was 194 days (95\% CI, 174-216, Fig. 3 ). Of the eyes, $37 \%$ were graded persistently as active during the 12 months of treatment. The median time between injections was 36 days $\left(Q_{1}, Q_{3} ; 28,56\right)$ while the lesions were graded as "active" and 42 days $\left(Q_{1}, Q_{3} ; 35,63\right)$ while graded "inactive."

\section{Eyes That Did Not Complete 12 Months of Follow- up}

A total of 230 eyes (17\%) either withdrew from treatment or were lost to follow-up over the observed 12-month interval (noncompleters). Median follow-up time for these eyes was 210 days $\left(\mathrm{Q}_{1}, \mathrm{Q}_{3} ; 111,302\right)$. At the index visit, noncompleters were similar to completers in most respects except for lower VA (mean 57.1 vs. 52.5, $P=0.0004, \mathrm{KS}$ test). The outcomes for noncompleters are shown in longitudinal profiles in Figure 4.

\section{Safety}

Ocular adverse events observed over 12 months follow-up are summarized in Table 5. The most common adverse event was patient-reported postinjection pain (45 instances). Two instances of infectious endophthalmitis were reported out of a total of 9162 injections.

\section{Discussion}

This analysis of outcome data that were collected prospectively and continuously from patients receiving treatment for

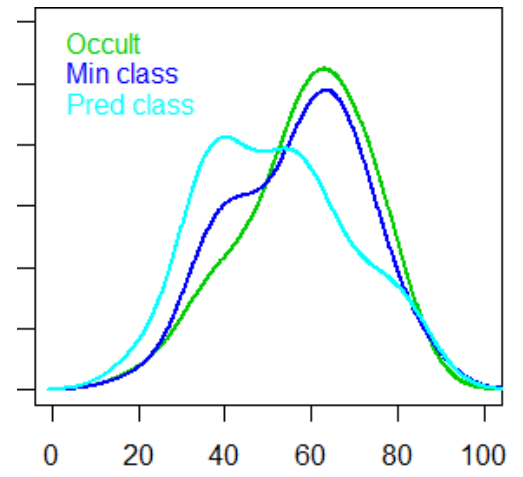

Index visual acuity (letters LogMAR)

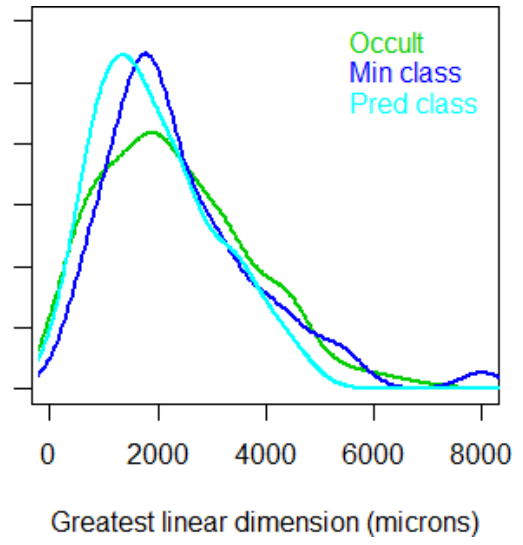

Greatest linear dimension (microns)

Figure 1. Density plots of VA (left) and greatest linear dimension (right) at the index visit by lesion type. 

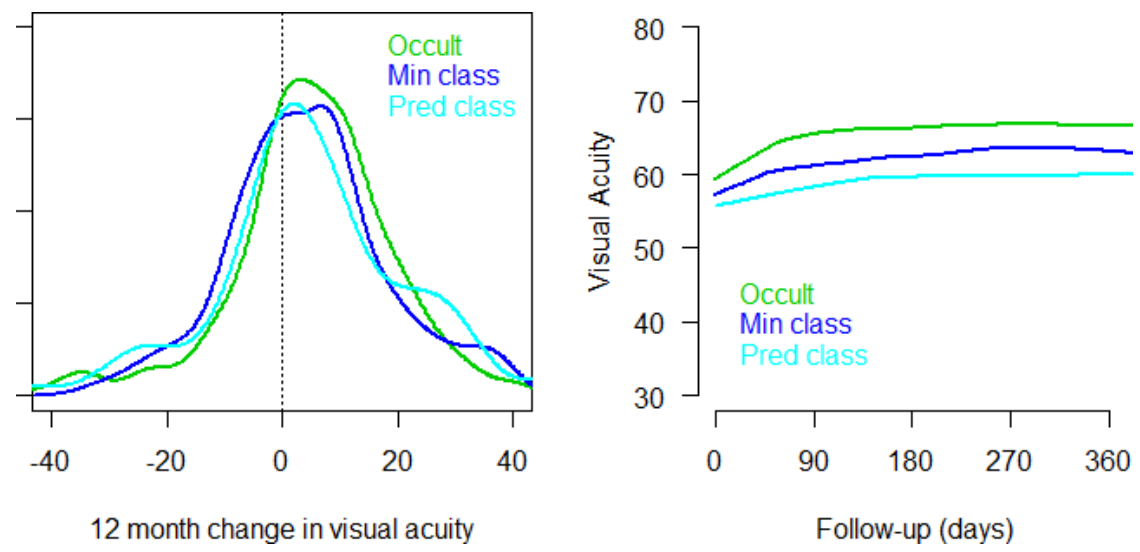

Figure 2. Density plot of within group changes at 12 months (left) and fitted Lowess lines showing subgroup changes in VA over 12 months (right).

exudative AMD has produced a number of observations on the use and outcomes of intravitreal therapy in routine practice. Mean VA of the main cohort improved significantly by +4.7 $\log$ MAR letters over the first 12 months of treatment with a mean of 7 injections. The mean VA of predominantly classic lesions improved slightly more than that of the minimally classic or occult groups, although eyes with predominantly classic lesions had lower VA at the index visit. Otherwise, lesion type and size made little difference to the pattern of treatment outcomes, of which the strongest predictor was VA at the first treatment visit. The median time to first grading of lesions as inactive was 194 days, with $37 \%$ still active at 12 months. Safety findings were similar to previous reports. These findings indicated that VEGF inhibitors achieve good outcomes for wet AMD when used in routine clinical practice.

Several other observational studies of intravitreal therapy for neovascular AMD have been reported recently. The Swedish Lucentis Quality Registry found a good improvement in VA after 3 injections of ranibizumab, but this subsequently dropped back to pretreatment levels. ${ }^{16}$ Patients in that study received a mean of only 4.8 injections over 12 months, fewer than in the present study. Similar results were found by the WAVE study and an analysis of the German reinjection scheme. ${ }^{17,18}$ These studies that recorded lower gains in mean visual acuities also had a lower mean number of injections.

An improvement in mean VA after the first 12 months of treatment that was more similar to our results has been reported by two other observational studies. A gain of 3.2 LOgMAR letters was found with a mean of 5.1 injections in the French Lumiere study of 551 patients. ${ }^{19}$ Menghini et al. reported a mean improvement of 5 letters with a mean of 4 injections in 204 eyes. $^{20}$

An overall mean improvement of $4.7 \log$ MAR letters in the current report still is somewhat less than was reported in phase 3 clinical trials of ranibizumab., ${ }^{2,3}$ However, the

Table 4. Coefficients From Mixed Effects Model Fit to 12-Month Longitudinal VA Data

\begin{tabular}{lcc}
\hline & Model Coefficient & $\boldsymbol{t}$ Value \\
\hline Index visual acuity & 0.9 & 62.93 \\
Index visit age & -0.03 & -1.00 \\
MC, relative to OC & -1.3 & -2.72 \\
PC, relative to OC & -0.5 & -0.98 \\
GLD $1000 \mu \mathrm{m}$ & -0.5 & -2.95 \\
1 y follow-up & 3.1 & 6.50 \\
\hline
\end{tabular}

improvements in these studies were measured primarily against the change of vision in the control groups. Verteporfin-treated eyes had lost a mean of 9.5 letters by 12 months in ANCHOR, while sham-treated eyes had lost 10.4 letters in MARINA. Seen in this light, the increase in VA found in the present analysis of outcomes of treated eyes in routine practice is reassuring. This was achieved with a mean of 7.0 injections, significantly more than was given in previously reported observational studies, ${ }^{16-20}$ out of potentially 13 that would be given with a strict monthly regimen. This frequency is similar to that of the CATT study, in which a mean of 6.9 injections were given to the ranibizumab PRN group and 7.7 to the bevacizumab PRN group. ${ }^{5}$

Median time to grading the lesion as "inactive" was 194 days. Of the lesions $37 \%$ were graded consistently as active throughout the first year of the study. As might be expected, these eyes received more injections. A related variable, presence of fluid at the 1-year visit, was reported in $81 \%$ of bevacizumab PRN and 56\% of ranibizumab monthly groups of the CATT study. ${ }^{5}$ It appears that reasonably good VA outcomes can be obtained despite many eyes remaining active much or all of the time.

Lesion characteristics, particularly lesion size (GLD) and type, did not affect the outcomes of this study significantly. Lesion type also had little effect on outcomes in retrospective analyses of MARINA and ANCHOR, in which mixed lesions had similar outcomes to purely classic or purely occult lesions. ${ }^{21,22}$

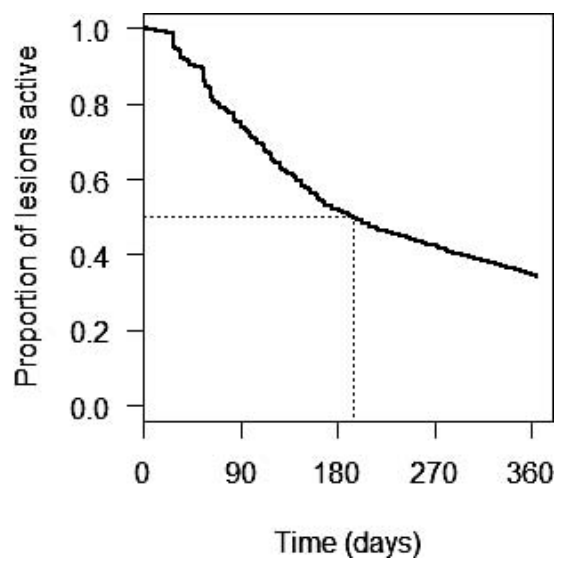

FiguRe 3. Kaplan-Meier plot of time from active lesion first being graded as inactive. 

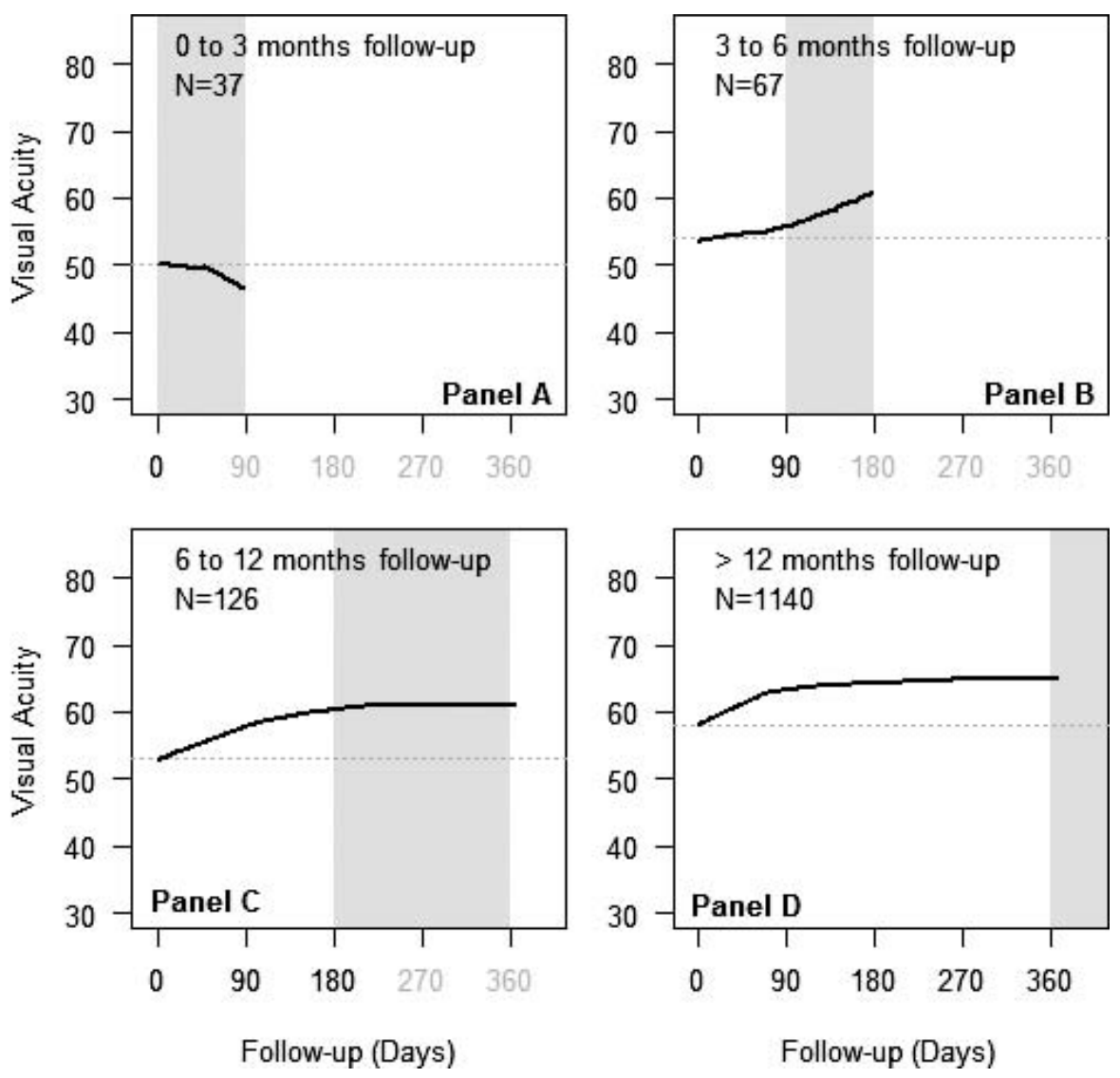

Figure 4. Fitted Lowess lines showing changes in VA over 12 months for noncompleters (A-C) and completers (D).

Menghini et al. also found no effect of lesion type on visual outcome after 24 months of treatment in another observational study. ${ }^{20}$ In a recent report from Comparison of AMD Treatment Trials, predominantly or minimally classic versus occult $\mathrm{CNV}$ was not included in the final multivariate model of change in VA at 1 year because it was not statistically significant. ${ }^{23}$ independently with less improvement in VA at 1 year in that study. Similarly, another recent report found no difference in VA outcome for occult, minimally classic or predominantly classic lesions in the PIER study. ${ }^{24}$

The rate of serious adverse events was consistent with previous experience. Infectious endophthalmitis occurred in 2 patients, an incidence of 2.2 per 10,000 injections. Noninfectious endophthalmitis was reported in 2 more cases. Retinal detachment occurred in 1 eye, an incidence of 1.1 per 10,000 injections; this is similar to the rate at which retinal

TABLE 5. Adverse Events

\begin{tabular}{lcc}
\hline & Frequency & Injections per AE \\
\hline Post injection pain reported & 45 & 204 \\
Hemorrhage reducing VA $>15$ & 5 & - \\
Retinal detachment & 1 & 9162 \\
Noninfectious endophthalmitis & 2 & 4581 \\
Infectious endophthalmitis & 2 & 4581 \\
RPE tear & 12 & 764 \\
Cataract extraction/other surgery & 15 & 611 \\
\hline
\end{tabular}

\footnotetext{
RPE, retinal pigment epithelium.
}

detachments are reported to occur in the general population. ${ }^{25}$ Mild adverse events appear to be underreported, since there were only 45 episodes of postinjection pain. This indicates that registries may not track accurately outcomes that clinicians do not believe are clinically significant.

This study, like all observational studies, has some limitations arising from the way in which data were collected. Subjective criteria, such as lesion activity or lesion type, may not be graded uniformly in observational studies, since they are reported by the treating physicians rather than a centralized Reading Center. Thus, these determinations may have lower internal validity than in a phase 3 clinical trial, but perhaps they still are meaningful, since this is how these clinically important determinations actually are being made in the real world. The measurement of LogMAR VA, the main outcome, is reasonably objective. Also, case selection and treatment regimens in observational studies may be very different to those of clinical trials and among different ophthalmologists. Nevertheless, the data presented showed generally consistent outcomes of treatment regimens, which appeared to be similar across the different centers (data not shown).

A number of further analyses can be performed on observational data that we presented here. A study of the efficacy of different treatment intensities will need to take into account "treatment by time" interactions (a treatment in the first 3 months is likely to have a greater effect than a treatment in the last 3 months), and the possibility that the outcome of treatment drives treatment intensity, with eyes responding poorly receiving more treatments than these that respond well, rather than vice versa. A study of poor responders would need to include not just the proportion of patients who, for 
example, lose 15 letters, but also analysis of their baseline characteristics, how the loss evolved over time and whether the causes could be identified by a case by case analysis referring back to the clinic notes in a selected subgroup. Treatment patterns and their different efficacies also can be identified: a pro re nata regimen will be revealed when treatments are given only when the lesion is graded as active, while a treat-and-extend regimen will have most treatments given when the lesion is graded as inactive.

The significance of data from observational studies is that they provide an indication of what is happening in routine clinical practice, in contrast to results of phase 3 clinical trials, which may or may not be achievable in general. The results we presented of intravitreal therapy for wet AMD are reasonably good, at least in the Australian centers that chose to participate. Further research is warranted to determine the functional implications of persistent activity and whether cohorts of patients receiving routine treatment do as well as those in phase 3 studies when they are matched more closely to participants in those studies.

\section{Acknowledgments}

Supported by a grant from the Eye Foundation (2007-2009) and a grant from the National Health and Medical Research Council, Australia (NHRMC 2010-1012), in part by NHMRC Clinical Research Fellowships (MCG, a Sydney University Medical Foundation Fellow, and RHG), and by the Walter and Gertrud Siegenthaler Foundation Zurich, Switzerland and the Swiss National Foundation (DB). The authors alone are responsible for the content and writing of this paper.

Disclosure: M.C. Gillies, Bayer (C, R), Novartis (F, C, R), Pfizer (C, R), Allergan (C, R), P; R. Walton, None; J.M. Simpson, None; J.J. Arnold, Novartis (C, R), Bayer (C, R); R.H. Guymer, Novartis (C, R), Bayer (C, R); I.L. McAllister, Novartis (C, R), Bayer (C, R); A.P. Hunyor, Novartis (C, R), Bayer (C, R), Zeiss (C, R); R.W. Essex, None; N. Morlet, None; D. Barthelmes, P

\section{References}

1. Holash J, Davis S, Papadopoulos N, et al. VEGF-Trap: a VEGF blocker with potent antitumor effects. Proc Natl Acad Sci US A. 2002;99:11393-11398.

2. Rosenfeld PJ, Brown DM, Heier JS, et al. Ranibizumab for neovascular age-related macular degeneration. $N$ Engl J Med. 2006;355:1419-1431.

3. Brown DM, Kaiser PK, Michels M, et al. Ranibizumab versus verteporfin for neovascular age-related macular degeneration. N Engl J Med. 2006;355:1432-1444.

4. Martin DF, Maguire MG, Fine SL, et al. Ranibizumab and bevacizumab for treatment of neovascular age-related macular degeneration: two-year results. Opbthalmology. 2012;119: 1388-1398.

5. Martin DF, Maguire MG, Ying GS, et al. Ranibizumab and bevacizumab for neovascular age-related macular degeneration. N Engl J Med. 2011;364:1897-1908.

6. Stewart MW. Aflibercept (VEGF Trap-eye): the newest antiVEGF drug. Br J Ophthalmol. 2012;96:1157-1158.

7. Traynor K. Aflibercept approved for macular degeneration. Am J Health Syst Pharm. 2012;69:6.

8. Lalwani GA, Rosenfeld PJ, Fung AE, et al. A variable-dosing regimen with intravitreal ranibizumab for neovascular agerelated macular degeneration: year 2 of the PrONTO Study. Am J Ophthalmol. 2009;148:43-58.e1.

9. Gupta OP, Shienbaum G, Patel AH, et al. A treat and extend regimen using ranibizumab for neovascular age-related macular degeneration clinical and economic impact. Ophthalmology. 2010;117:2134-2140.
10. Gillies MC, Walton R, Liong J, et al. Efficient capture of high quality data on outcomes of treatment for macular diseases: the Fight Retinal Blindness! Project [published online ahead of print June 3, 2013]. Retina. doi:10.1097/IAE.0b013e318296b271.

11. Cleveland WS. Robust locally weighted regression and smoothing scatterplots. J Am Stat Assoc. 1979;74:829-836.

12. Cleveland W. LOWESS: a program for smoothing scatterplots by robust locally weighted regression. Am Stat. 1981;35:54.

13. Kleinbaum DG, Klein M. Chapter 2: Kaplan-Meier survival curves and the log-rank test. In: Survival Analysis: $A$ SelfLearning Text. New York, NY: Springer; 2005:45-82.

14. R: A Language and Environment for Statistical Computing: Foundation for Statistical Computing.

15. DiCiccio TJ, Efron B. Bootstrap confidence intervals (with Discussion). Statistical Science. 1996;11:189-228.

16. Hjelmqvist L, Lindberg C, Kanulf $\mathrm{P}$, et al. One-year outcomes using ranibizumab for neovascular age-related macular degeneration: results of a prospective and retrospective observational multicentre study. J Ophthalmol. 2011;2011:405724.

17. Finger RP, Wiedemann P, Blumhagen F, et al. Treatment patterns, visual acuity and quality-of-life outcomes of the WAVE study-A noninterventional study of ranibizumab treatment for neovascular age-related macular degeneration in Germany [published online ahead of print November 22, 2012]. Acta Ophthalmol. doi:10.1111/j.1755-3768.2012. 02493.x.

18. Heimes B, Lommatzsch A, Zeimer M, et al. Long-term visual course after anti-VEGF therapy for exudative AMD in clinical practice evaluation of the German reinjection scheme. Graefe's Arch Clin Exp Ophthalmol. 2011;249:639-644.

19. Cohen SY, Mimoun G, Oubraham H, et al. Changes in visual acuity in patients with wet age-related macular degeneration treated with intravitreal ranibizumab in daily clinical practice: the LUMIERE study. Retina. 2012;33:474-481.

20. Menghini M, Kloeckener-Gruissem B, Fleischhauer J, et al. Impact of loading phase, initial response and CFH genotype on the long-term outcome of treatment for neovascular agerelated macular degeneration. PLoS One. 2012;7:e42014.

21. Boyer DS, Antoszyk AN, Awh CC, et al. Subgroup analysis of the MARINA study of ranibizumab in neovascular age-related macular degeneration. Ophthalmology. 2007;114:246-252.

22. Kaiser PK, Brown DM, Zhang $K$, et al. Ranibizumab for predominantly classic neovascular age-related macular degeneration: subgroup analysis of first-year ANCHOR results. Am J Ophthalmol. 2007;144:850-857.

23. Ying GS, Huang J, Maguire MG, et al. Baseline predictors for one-year visual outcomes with ranibizumab or bevacizumab for neovascular age-related macular degeneration. Ophthalmology. 2013;120:122-129.

24. Brown DM, Tuomi L, Shapiro H. Anatomical measures as predictors of visual outcomes in ranibizumab-treated eyes with neovascular age-related macular degeneration. Retina. 2013;33:23-34.

25. Haimann MH, Burton TC, Brown CK. Epidemiology of retinal detachment. Arch Ophthalmol. 1982;100:289-292.

\section{APPENDIX}

Fight Retinal Blindness Investigators: Eye Surgeons Miranda, Miranda, NSW (A. Hunt); Eye Associates, Sydney, NSW (M. Gillies and A. Hunt); Retina Associates, Chatswood, NSW (A.H. Hunyor, S. Fraser-Bell, and C. Younan); Marsden Eye Specialists, Parramatta, NSW (J. Arnold and D. Chan); Gladesville Eye Specialists, Gladesville, NSW (S. Young); Hornsby Eye Specialists, Hornsby, NSW (S. Lal); Northern Rivers Eye Surgeons, Lismore, NSW (G. Clark and N. Aboud); Eyemedics, Adelaide, SA (S. Lake, R. Phillips, and M. Perks); Canberra Hospital, 
Garran, ACT (R. Essex); Cairns Eye and Laser Clinic, Cairns, QLD (A. Field); Queensland Eye Institute, South Brisbane, QLD (T. Kwan); Lions Eye Institute, Nedlands, WA (I. McAllister, F. Chen, T. Isaacs, and I. Constable); Centre for Eye Research Australia, East Melbourne, VIC (R. Guymer, R. Troutbeck, and D. Louis); Cheltenham Eye Centre, Cheltenham; Bayside Eye Specialists, Brighton East; Southern Eye Centre, Frankston, VIC (D. Louis); Victoria Parade Eye Consultants, Fitzroy, VIC (R. Guymer, L. Lim, and A. Harper); Doncaster Eye Centre,
Doncaster, VIC (S. Wickremansinghe and L.P. Chow); Caulfield Eye Clinic, Caulfield, VIC (R. Troutbeck and S. Wickremasinghe); Specialists Eye Group, Glen Waverly, VIC (S. Wickremasinghe and L.P. Chow); Eye Institute, Auckland, NZ (P. Hadden); ADHB, Auckland, NZ (D. Squirrell); Milford Eye Clinic, Auckland, NZ (D. Squirrell); University Hospital Zurich, University of Zurich, Zurich Switzerland (D. Barthelmes); Retina Specialist Auckland, NZ (D. Sharp, R. Barnes and P. Hadden). 